\title{
Avaliação de caracteres morfológicos úteis na identificação de plantas poliplóides de melancia
}

\author{
Flávio de F. Souza ${ }^{1}$; Manoel A. de Queiróz ${ }^{2}$ \\ ${ }^{1}$ Embrapa Rondônia, C. Postal 406, 78900-970 Porto Velho-RO; E-mail: flaviofs@ @pafro.embrapa.br; ${ }^{2}$ UNEB-DTCS C. Postal 171, \\ 48900-000 Juazeiro-BA; E-mail: manoelqueiroz@uol.com.br
}

\section{RESUMO}

Visando ao estudo da variação quantitativa de caracteres morfológicos em genótipos diplóides, triplóides e tetraplóides de melancia [Citrullus lanatus (Thunb.) Matsum. \& Nakai], três linhagens diplóides, três linhagens tetraplóides e três híbridos triplóides foram avaliados quanto ao número de cloroplastos por estômato foliar (NCF); largura e comprimento foliar (LFH e CFH); relação largura/ comprimento foliar (LF/CF); diâmetro de caule (DCE); diâmetro da corola em flores masculinas e femininas (DCM e DCF); diâmetro do ovário (DOV); peso de fruto (PMF), diâmetro transversal e longitudinal de fruto (DTF e DLF); relação diâmetro transversal/diâmetro longitudinal (DT/DL) e espessura média da casca (EMC). Foi utilizado delineamento de blocos casualizados com três repetições e parcelas de cinco plantas. Realizou-se análise univariada, segundo o modelo hierárquico, considerando-se o nível de ploidia como o fator principal. Os genótipos foram agrupados em dendrograma baseado na distância generalizada de Mahalanobis e também dispostos em um plano cartesiano, utilizando-se os escores das duas primeiras variáveis canônicas. A contribuição relativa das variáveis para a composição dos grupos de divergência foi estimada por meio do método de Singh e a matriz de correlação foi obtida utilizando a análise de componentes principais. O NCF apresentou maior importância relativa (41\%) para a formação dos grupos de divergência, enquanto, os caracteres DMF, EMC e PMF apresentaram contribuição inferior a $1,0 \%$. As variáveis $\mathrm{NCF}, \mathrm{LF} / \mathrm{CF}, \mathrm{DCP}, \mathrm{DCF}, \mathrm{DCM}$, DOV e DT/DL, analisadas conjuntamente, mostraram-se eficientes para a discriminação de plantas diplóides, triplóides e tetraplóides, e, portanto são recomendadas para auxiliar nos programas de melhoramento de melancia, que visem à obtenção de plantas poliplóides.

\begin{abstract}
Evaluation of morphological characters useful in the identification of poliploid watermelon plants

The quantitative variation of the morphological characters in diploid, triploid and tetraploid genotypes of watermelon [Citrullus lanatus (Thunb.) Matsum. \& Nakai] was evaluated in three diploids, three tetraploids and three triploids hybrids, in relation to the number of chloroplasts per leaf stomata (NCF); width and length of the leaves (LFH e CFH); leaf width/length ratio (LF/CF); stem diameter (DCE); petal diameter in male and female flowers (DCM and DCF); ovary diameter (DOV); fruit weight (PMF); transversal and axial fruit diameter (DTF and DLF); fruit diameter axial/diameter transversal ratio (DL/DT) and rind thickness (EMC). A randomized block design was employed with three replications and five plants per plot. A nested analysis was performed and the ploidy level was considered the main factor. The genotypes were clustered at a dendrogram based on generalized Mahalanobis distance and also plotted on Cartesian plain using scores of the first and second canonic variables. Relative contribution of the variables to clustering was estimated by the Singh Method and the matrix of correlation was obtained using the Principal Component Analysis. The NCF presented higher relative importance $(41 \%)$ to set divergence clusters, while DCF, DCM, DOV and DT/ DL when analyzed together showed themselves efficient to discriminate diploids, triploids and tetraploid plants. So, they are recommended to aid watermelon breeding programs to obtain polyploid plants.
\end{abstract}

Keywords: Citrullus lanatus, polyploidy, multivariated analysis.

Palavras-chave: Citrullus lanatus, poliploidia, análise multivariada.

\section{(Recebido para publicação em 25 de setembro de 2003 e aceito em 24 de junho de 2004)}

$\mathrm{O}$ frutos de melancia sem sementes são produzidos em plantas triplóides, as quais são cultivadas por meio de sementes híbridas provenientes do cruzamento entre plantas tetraplóides e diplóides. As plantas tetraplóides são normalmente obtidas pelo tratamento de sementes ou plântulas diplóides com colchicina, o qual constitui uma das técnicas mais utilizadas para a duplicação do número cromossômico de espécies vegetais.

Em geral, os métodos de indução de poliploidia apresentam baixa eficiência, de modo que a maioria das plantas tratadas permanece diplóide ou apresenta níveis intermediários de ploidia. Como apenas as plantas tetraplóides são desejáveis, faz-se necessário identificá-las dentro do conjunto de plantas tratadas. A identificação do nível de ploidia, em plantas submetidas à duplicação cromossômica, pode ser realizada diretamente por meio da contagem do número de cromossomos em células mitóticas ou meióticas (Kihara, 1951; Guerra, 1983), no entanto, esse método é bastante trabalhoso e muito demorado, sobretudo quando há muitas amostras para serem analisadas (Qin e Rotino, 1995).

A avaliação de determinadas características da planta, tais como aspectos morfológicos, tamanho do grão de pólen, número de cloroplastos por par de células-guarda, tamanho e densidade dos estômatos foliares, pode ser útil para inferir o nível de ploidia de plantas submetidas à indução de poliploidia (Souza, 2000). Para tanto, o uso de técnicas multivariadas é útil sobretudo quando se trata de um conjunto heterogêneo de indivíduos, uma vez que permite quantificar a diversidade presente, possibilitando a identificação de indivíduos discrepantes, além de explicar as relações existentes entre as variáveis analisadas.

A análise da divergência genética pode ser realizada por meio de técnicas 
biométricas ou por processos preditivos. Os métodos preditivos tomam por base diferenças fenotípicas apresentadas pelos indivíduos, as quais podem ser quantificadas em termos de medidas de dissimilaridade. Os mais utilizados no melhoramento genético de plantas são a análise por componentes principais, a análise por variáveis canônicas e os métodos aglomerativos. Segundo Cruz e Regazzi (1997), o emprego de métodos aglomerativos tem como objetivo a reunião dos progenitores em grupos, de modo que haja homogeneidade dentro do grupo e heterogeneidade entre os grupos. Estes métodos dependem da estimativa prévia de medidas de dissimilaridade como a distância Euclidiana ou a distância generalizada de Mahalanobis.

$\mathrm{Na}$ análise de componentes principais, um conjunto de variáveis é transformado em outro conjunto de dimensão equivalente, no qual as novas variáveis são funções lineares das variáveis originais e são independentes entre si. Quando utilizada para avaliar a divergência genética em um grupo de genótipos, a técnica possibilita estudar a dispersão dos mesmos em um sistema de eixos cartesianos nos quais o aproveitamento da variabilidade disponível seja maximizado. Por outro lado, a análise de variáveis canônicas trata-se de um processo de avaliação do grau de similaridade genética entre um grupo de progenitores que leva em consideração a covariância residual e a covariância fenotípica entre as características avaliadas. O uso de variáveis canônicas possibilita a identificação de indivíduos similares em gráficos de dispersão bi ou tridimensionais. No entanto, a viabilidade do uso desta técnica depende da concentração da variabilidade nas duas primeiras variáveis (Cruz e Regazzi, 1997).

O presente trabalho teve como objetivo determinar, quantitativamente, por meio de técnicas de análise uni e multivariadas, a capacidade que alguns caracteres morfológicos apresentam de discriminar o nível de ploidia em plantas de melancia.

\section{MATERIAL E MÉTODOS}

$\mathrm{O}$ experimento foi realizado na $\mathrm{EE}$ de Bebedouro, pertencente à Embrapa
Semi-Árido, em Petrolina (PE), à latitude de $09^{\circ} 09^{\prime} \mathrm{S}$, longitude de $40^{\circ} 22^{\prime}$ $\mathrm{W}$ e altitude de $360 \mathrm{~m}$. A região apresenta clima semi-árido, quente (BSh) e solo do tipo Latossolo Amarelo.

Os grupos de ploidia foram formados pelas linhagens LD07, LD09, LDCC01 (diplóides), LT07, LT09, LTCC01 (tetraplóides) e pelos híbridos LT07xCS, LT09xCS e LTCC01xCS (triplóides). As linhagens diplóides foram extraídas do programa de melhoramento genético de cucurbitáceas da Embrapa Semi-Árido. As progênies tetraplóides foram obtidas a partir das linhagens diplóides pela indução de poliploidia com colchicina. Os híbridos triplóides foram obtidos pelo cruzamento das progênies tetraplóides com a cultivar diplóide Crimson Sweet.

Empregou-se delineamento de blocos ao acaso com três repetições, formadas por parcelas de sete plantas. De cada parcela, foram amostradas as cinco plantas centrais, nas quais foram avaliados 1) comprimento foliar máximo (CFH) e largura foliar máxima (LFH), medidos com régua, em dez folhas totalmente expandidas, tomadas no terço mediano de cada planta amostrada; 2) diâmetro do caule (DCE), medido com paquímetro, em cinco internódios do terço mediano de cada planta amostrada; 3) diâmetro da corola de flores masculinas (DCM); 4) diâmetro da corola de flores femininas (DCF) e 5) diâmetro do ovário (DOV), medidos com régua e com paquímetro em dez flores, de cada uma das plantas amostradas, durante o período de antese; 6) número de cloroplastos por estômato foliar (NCF), pela contagem de cloroplastos, com microscópio ótico, sob a objetiva de 40x, em dez estômatos tomados ao acaso, em amostras da epiderme inferior de três folhas do terço mediano de cada uma das plantas amostradas; 7) peso médio de fruto (PMF); 8) diâmetro transversal do fruto (DTF); 9) diâmetro longitudinal do fruto (DLF) e 10) espessura média da casca (EMC) em uma amostra de cinco frutos tomados ao acaso, em cada parcela.

Inicialmente, os grupos de ploidia foram submetidos à análise de variância, individualmente, para obtenção dos quadrados médios, os quais foram utili- zados na verificação da homogeneidade de variância, por meio do Teste de Hartley (Ramalho et al., 2000). Na análise, também foram determinados os coeficientes de variação intra-grupo. As variáveis que apresentaram variâncias homogêneas foram novamente analisadas, segundo um esquema de classificação hierárquica, no qual os níveis de ploidia (diplóide, triplóide e tetraplóide) foram tomados como fatores principais, dentro dos quais dispuseram-se os genótipos (LD07, LD09, LDCC01, LT07, LT09, LTCC01, LT07xCS, LT09xCS e LTCC01xCS). Empregouse o modelo a seguir, no qual foram considerados aleatórios apenas os efeitos do erro experimental.

$$
Y_{i j k}=m+P_{i}+G_{(i) k}+b_{j}+e_{(i j k)},
$$

em que: $Y_{i j k}=$ é a observação do tratamento referente ao nível de ploidia i e ao genótipo k, no bloco j; $m$ = é a média geral; $P_{i}=$ é o efeito do nível de ploidia i; $G_{(i) k}=$ é o efeito do genótipo k, dentro do nível de ploidia $i ; b_{j}=$ é o efeito do bloco j; $e_{(i j k)}=$ é o efeito do erro experimental.

As médias de cada variável foram comparadas pelo teste de Tukey a 5\% de probabilidade. As medidas de dissimilaridade foram calculadas por meio da distância generalizada de Mahalanobis e o agrupamento dos genótipos foi realizado estabelecendose um dendrograma, com base no método de Ward. Alternativamente, os genótipos foram plotados em um plano cartesiano, utilizando-se os escores das duas primeiras variáveis canônicas. A contribuição relativa das variáveis para a divergência genética foi determinada utilizando o critério proposto por Singh e a matriz de correlação entre as variáveis foi obtida através da análise de componentes principais. Todos os procedimentos foram realizados utilizando-se o Programa Genes, versão Windows 2001.

\section{RESULTADOS E DISCUSSÃO}

Foram verificadas diferenças significativas entre os grupos de ploidia para todas as características avaliadas, o que sugere que cada variável estudada pode ser utilizada para separar pelo menos dois, dos três grupos estabelecidos (Tabela 1). 
Tabela 1. Análise de variância em caracteres morfológicos de genótipos diplóides, triplóides e tetraplóides de melancia. Petrolina, Embrapa Semi-Árido, 2000.

\begin{tabular}{|c|c|c|c|c|c|c|c|c|c|c|c|c|c|c|}
\hline \multirow{2}{*}{ FV } & \multirow{2}{*}{ GL } & \multicolumn{13}{|c|}{ Quadrado médio } \\
\hline & & LFH1 & CFH & LF/CF & DCE & DCF & DCM & DOV & NCF & PMF & DTF & DLF & DUDT & EMC \\
\hline Blocos & 2 & 3,400 & 3,743 & 0,003 & 0,008 & 0,014 & 0,001 & 0,002 & 0,084 & 2,914 & 2,471 & 7,208 & 0,002 & 0,049 \\
\hline Tratamentos & 8 & 25,187 & 10,550 & 0,120 & 0,038 & 0,867 & 0,832 & 0,135 & 46,338 & 24,291 & 35,872 & 38,968 & 0,023 & 0,114 \\
\hline $\begin{array}{l}\text { Grupos } \\
\text { ploidia }\end{array}$ & 2 & 8,357 & 9,721 & 0,429 & 0,100 & 2,613 & 2,748 & 0,480 & 183,603 & 8,664 & 8,983 & 25,321 & 0,073 & 0,239 \\
\hline $\begin{array}{l}\text { Genótipo/ } \\
\text { ploidia }\end{array}$ & 6 & 17,464 & 10,826 & 0,017 & 0,017 & 0,284 & 0,193 & 0,020 & 0,582 & 29,500 & 44,835 & 43,517 & 0,007 & 0,073 \\
\hline gen/grupo 1 & 2 & 4,254 & 2,703 & 0,003 & 0,001 & 0,191 & 0,008 & 0,003 & 0,388 & 24,472 & 50,073 & 36,051 & 0,015 & 0,059 \\
\hline gen/grupo 2 & 2 & 4,563 & 4,088 & 0,023 & 0,002 & 0,028 & 0,063 & 0,024 & 0,021 & 42,271 & 43,258 & 59,871 & 0,002 & 0,092 \\
\hline gen/grupo 3 & 2 & 43,573 & 25,688 & 0,023 & 0,049 & 0,634 & 0,508 & 0,034 & 1,338 & 21,757 & 41,173 & 34,630 & 0,004 & 0,068 \\
\hline Resíduo & 16 & 2,385 & 1,899 & 0,003 & 0,002 & 0,045 & 0,014 & 0,003 & 0,326 & 0,855 & 0,871 & 1,520 & 0,001 & 0,017 \\
\hline Total & 26 & & & & & & & & & & & & & \\
\hline F entre & & $20,3^{* *}$ & $5,1^{*}$ & $159,2^{* *}$ & $57,3^{* *}$ & $58,2^{* *}$ & $190,2^{* *}$ & $188,8^{* *}$ & $563,7^{* *}$ & $10,1^{* *}$ & $10,3^{* *}$ & $16,7^{* *}$ & $135,2^{\text {* * }}$ & $14,0^{\text {* * }}$ \\
\hline F dentro & & $7,3^{* *}$ & $5,7^{* *}$ & $6,1^{\text {** }}$ & $9,9^{* *}$ & $6,3^{* *}$ & $13,4^{\text {* * }}$ & $8,0^{* *}$ & $1,8 \mathrm{~ns}$ & $34,5^{* *}$ & $51,5^{* *}$ & $28,6^{* *}$ & $12,2^{* *}$ & $4,3^{* *}$ \\
\hline
\end{tabular}

${ }^{1} \mathrm{LFH}=$ largura foliar máxima, $\mathrm{CFH}=$ Comprimento foliar máximo, $\mathrm{LF} / \mathrm{CF}=$ relação entre a largura foliar máxima e o comprimento foliar máximo, $\mathrm{DCE}=$ diâmetro do caule, $\mathrm{DCM}=$ diâmetro da corola de flores masculinas, $\mathrm{DCF}=$ diâmetro da corola de flores femininas, $\mathrm{DOV}$ $=$ diâmetro do ovário, $\mathrm{NCF}=$ Número de cloroplastos por estômato foliar, $\mathrm{PMF}=$ peso médio de fruto, $\mathrm{DTF}=$ diâmetro transversal do fruto, $\mathrm{DLF}=$ diâmetro longitudinal do fruto, DL/DT = Relação entre o diâmetro longitudinal e o diâmetro transversal do fruto e EMC $=$ espessura média da casca.

Tabela 2. Avaliação de caracteres morfológicos em genótipos diplóides, triplóides e tetraplóides de melancia. Petrolina, Embrapa Semi-Árido, 2000.

\begin{tabular}{|c|c|c|c|c|c|c|}
\hline \multirow{3}{*}{$\frac{\text { Caracteres }}{\mathrm{LFH}^{1}(\mathrm{~cm})}$} & \multicolumn{4}{|c|}{ Grupos } & \multirow{3}{*}{$\begin{array}{l}\text { Média } \\
20,76\end{array}$} & \multirow{3}{*}{$\begin{array}{c}\text { CV (\%) } \\
7,4\end{array}$} \\
\hline & \multirow{2}{*}{$\begin{array}{l}\text { Diplóide } \\
18,09 \mathrm{~b}^{2}\end{array}$} & \multicolumn{2}{|c|}{ Triplóide } & \multirow{2}{*}{$\begin{array}{c}\text { Tetraplóide } \\
22,20 \text { a }\end{array}$} & & \\
\hline & & 22,00 & $a$ & & & \\
\hline $\mathrm{CFH}(\mathrm{cm})$ & $18,67 \mathrm{~b}$ & 20,47 & $a$ & $18,69 \mathrm{~b}$ & 19,28 & 7,1 \\
\hline LF/CF & $0,95 \mathrm{c}$ & 1,23 & $b$ & $1,38 \mathrm{a}$ & 1,18 & 4,4 \\
\hline $\mathrm{DCP}(\mathrm{cm})$ & $0,55 \mathrm{c}$ & 0,66 & $\mathrm{~b}$ & $0,77 \mathrm{a}$ & 0,66 & 6,3 \\
\hline $\mathrm{DCE}(\mathrm{cm})$ & $2,89 \mathrm{c}$ & 3,56 & $b$ & $3,95 \mathrm{a}$ & 3,46 & 6,1 \\
\hline $\mathrm{DCM}(\mathrm{cm})$ & $2,49 \mathrm{c}$ & 3,30 & $\mathrm{~b}$ & $3,54 \mathrm{a}$ & 3,11 & 3,9 \\
\hline DOV (cm) & $0,95 \mathrm{c}$ & 1,23 & $b$ & $1,41 \mathrm{a}$ & 1,20 & 4,2 \\
\hline $\operatorname{NCF}(\mathrm{cm})$ & $10,60 \mathrm{c}$ & 15,10 & $b$ & $19,60 \mathrm{a}$ & 15,13 & 3,8 \\
\hline PMF (kg) & $5,92 \mathrm{~b}$ & 7,66 & $a$ & $6,00 \mathrm{~b}$ & 6,52 & 14,2 \\
\hline DTF (cm) & $20,90 \mathrm{~b}$ & 22,90 & a & $22,00 a b$ & 21,94 & 4,3 \\
\hline $\mathrm{DLF}(\mathrm{cm})$ & $24,20 \mathrm{a}$ & 24,70 & $a$ & $21,60 \mathrm{~b}$ & 23,51 & 5,2 \\
\hline DL/DT & $1,17 \mathrm{a}$ & 1,07 & $b$ & $0,98 \mathrm{c}$ & 1,08 & 2,2 \\
\hline $\mathrm{EMC}(\mathrm{cm})$ & $1,10 \mathrm{~b}$ & 1,40 & $a$ & $1,20 \mathrm{~b}$ & 1,24 & 10,5 \\
\hline
\end{tabular}

${ }^{1} \mathrm{LFH}=$ largura foliar máxima, $\mathrm{CFH}=$ Comprimento foliar máximo, $\mathrm{LF} / \mathrm{CF}=$ relação entre a largura foliar máxima e o comprimento foliar máximo, $\mathrm{DCE}=$ diâmetro do caule, $\mathrm{DCM}=$ diâmetro da corola de flores masculinas, $\mathrm{DCF}=$ diâmetro da corola de flores femininas, $\mathrm{DOV}=$ diâmetro do ovário, $\mathrm{NCF}=$ Número de cloroplastos por estômato foliar, $\mathrm{PMF}=$ peso médio de fruto, $\mathrm{DTF}=$ diâmetro transversal do fruto, DLF = diâmetro longitudinal do fruto, $\mathrm{DL} / \mathrm{DT}=$ Relação entre o diâmetro longitudinal e o diâmetro transversal do fruto e EMC = espessura média da casca.

${ }^{2}$ Médias seguidas da mesma letra, na linha, não diferem pelo teste de Tukey em nível de 5\% de probabilidade.

Apenas o número médio de cloroplastos por estômato foliar (NCF) apresentou variação homogênea dentro dos três grupos $(1,8 \mathrm{~ns})$, indicando que houve maior constância dessa variável entre diferentes genótipos com o mesmo número cromossômico (Tabela 1). Essa propriedade faz do NCF um im- portante critério para identificação indireta de plantas diplóides, triplóides e tetraplóides. As diferenças significativas observadas nas demais variáveis são atribuídas à divergência fenotípica dos genótipos que compunham cada grupo.

Com base no teste de comparação de médias (Tabela 2) foi possível veri- ficar que nem todas as diferenças observadas entre os três grupos relacionaram-se com a variação cromossômica. Apenas os caracteres LF/CF, DCE, DCF, DCM, DOV, NCF e DT/DL apresentaram relação direta com o aumento do nível de ploidia, permitindo separação dos três grupos. No caso da avaliação dos frutos, com exceção da relação diâmetro transversal/diâmetro longitudinal, todas as variáveis manifestaram maiores médias em nível dos genótipos triplóides, o que demonstra que esses caracteres são bastante influenciados pela ocorrência de efeitos heteróticos e, portanto não permitem a discriminação dos grupos de ploidia.

Pela análise prévia da matriz dos coeficientes de correlação fenotípica entre os caracteres estudados (Tabela 3) constatou-se que a variável NCF, que foi o melhor indicador do nível de ploidia, apresentou-se estreitamente correlacionada com os caracteres LF/ CF, DCE, DCF, DCM, DOV e DT/DL, o que confirma a eficiência dos mesmos na determinação indireta dos três grupos de ploidia.

A variável NCF foi a que apresentou maior importância relativa (41\%) para a formação dos grupos de divergência. Por outro lado, a contribuição relativa dos caracteres DTF, EMC e PMF foi inferior a $1,0 \%$, denotando que os mesmos tiveram importância míni- 
Tabela 3. Coeficientes de correlações fenotípicas entre caracteres morfológicos de caule, folha, flor e fruto em plantas de melancia diplóides, triplóides e tetraplóides. Petrolina, Embrapa Semi-Árido, 2000.

\begin{tabular}{|c|c|c|c|c|c|c|c|c|c|c|c|c|c|}
\hline & LFH & CFH & LF/CF & DCE & DCF & DCM & DOV & NCF & PMF & DTF & DLF & DL/DT & EMC \\
\hline$\overline{\mathrm{LFH} 1}$ & 1,0000 & 0,7837 & 0,6640 & 0,8959 & 0,2460 & 0,4559 & 0,6880 & 0,6688 & $-0,4424$ & $-0,4263$ & $-0,6399$ & $-0,5539$ & 0,2436 \\
\hline $\mathrm{CFH}$ & & 1,0000 & 0,1240 & 0,4754 & $-0,3342$ & $-0,0907$ & 0,1440 & 0,0755 & $-0,5575$ & $-0,6341$ & $-0,5523$ & 0,0012 & 0,1535 \\
\hline LF/CF & & & 1,0000 & 0,8272 & 0,8374 & 0,9336 & 0,9972 & 0,9269 & 0,0004 & 0,1089 & $-0,3395$ & $-0,8903$ & 0,3252 \\
\hline DCE & & & & 1,0000 & 0,4839 & 0,6178 & 0,8604 & 0,8524 & $-0,3196$ & $-0,2416$ & $-0,5929$ & $-0,7492$ & 0,1558 \\
\hline DCF & & & & & 1,0000 & 0,9310 & 0,8133 & 0,8130 & 0,4029 & 0,5401 & 0,0989 & $-0,8550$ & 0,3493 \\
\hline $\mathrm{DCM}$ & & & & & & 1,0000 & 0,9153 & 0,8373 & 0,2781 & 0,3769 & $-0,0522$ & $-0,8406$ & 0,3983 \\
\hline DOV & & & & & & & 1,0000 & 0,9334 & $-0,0324$ & 0,0758 & $-0,3718$ & $-0,8858$ & 0,2901 \\
\hline NCF & & & & & & & & 1,0000 & $-0,0381$ & 0,0800 & $-0,3611$ & $-0,9071$ & 0,2973 \\
\hline PMF & & & & & & & & & 1,0000 & 0,9760 & 0,9370 & $-0,0555$ & 0,5668 \\
\hline DTF & & & & & & & & & & 1,0000 & 0,8758 & $-0,2151$ & 0,5007 \\
\hline DLF & & & & & & & & & & & 1,0000 & 0,2668 & 0,4155 \\
\hline DL/DT & & & & & & & & & & & & 1,0000 & $-0,2903$ \\
\hline EMC & & & & & & & & & & & & & 1,0000 \\
\hline
\end{tabular}

${ }^{1} \mathrm{LFH}=$ largura foliar máxima, $\mathrm{CFH}=$ Comprimento foliar máximo, LF/CF = relação entre a largura foliar máxima e o comprimento foliar máximo, $\mathrm{DCE}=$ diâmetro do caule, $\mathrm{DCM}=$ diâmetro da corola de flores masculinas, $\mathrm{DCF}=$ diâmetro da corola de flores femininas, $\mathrm{DOV}$ $=$ diâmetro do ovário, $\mathrm{NCF}=$ Número de cloroplastos por estômato foliar, $\mathrm{PMF}=$ peso médio de fruto, $\mathrm{DTF}=$ diâmetro transversal do fruto, $\mathrm{DLF}=$ diâmetro longitudinal do fruto, $\mathrm{DT} / \mathrm{DL}=$ Relação entre o diâmetro longitudinal e o diâmetro transversal do fruto e EMC $=$ espessura média da casca.

ma para o agrupamento dos genótipos avaliados.

Como as duas primeiras variáveis canônicas explicaram mais de $80 \%$ da variação total, a dispersão gráfica dos escores em relação à primeira e à segunda variáveis canônicas pôde ser utilizada para a formação dos grupos divergentes. Na representação gráfica dos genótipos sobre o plano cartesiano (Figura 1), verifica-se uma nítida distribuição dos nove genótipos, formando três grupos. Observa-se que os genótipos LDCC01, LTCC01xCS e LTCC01, embora tenham sido plotados adequadamente conforme os seus níveis de ploidia, apresentaram comportamento diferenciado dentro de cada grupo, distanciando-se dos seus equivalentes diplóides, triplóides e tetraplóides, respectivamente. Essa variação deveu-se ao fato de que os genótipos considerados descendem de progênies de autofecundação de uma população espontânea coletada no Nordeste brasileiro e apresentam atrasado nível de melhoramento (Souza, 2000). Por outro lado, as linhagens LT07 e LT09 derivam de um programa de retrocruzamentos que tem como genitor recorrente a cultivar Crimson Sweet. A divergência foi mais pronunciada dentro dos grupos diplóide e tetraplóide. A maior coesão do grupo triplóide deve-se ao fato de que todos os híbridos têm em comum o

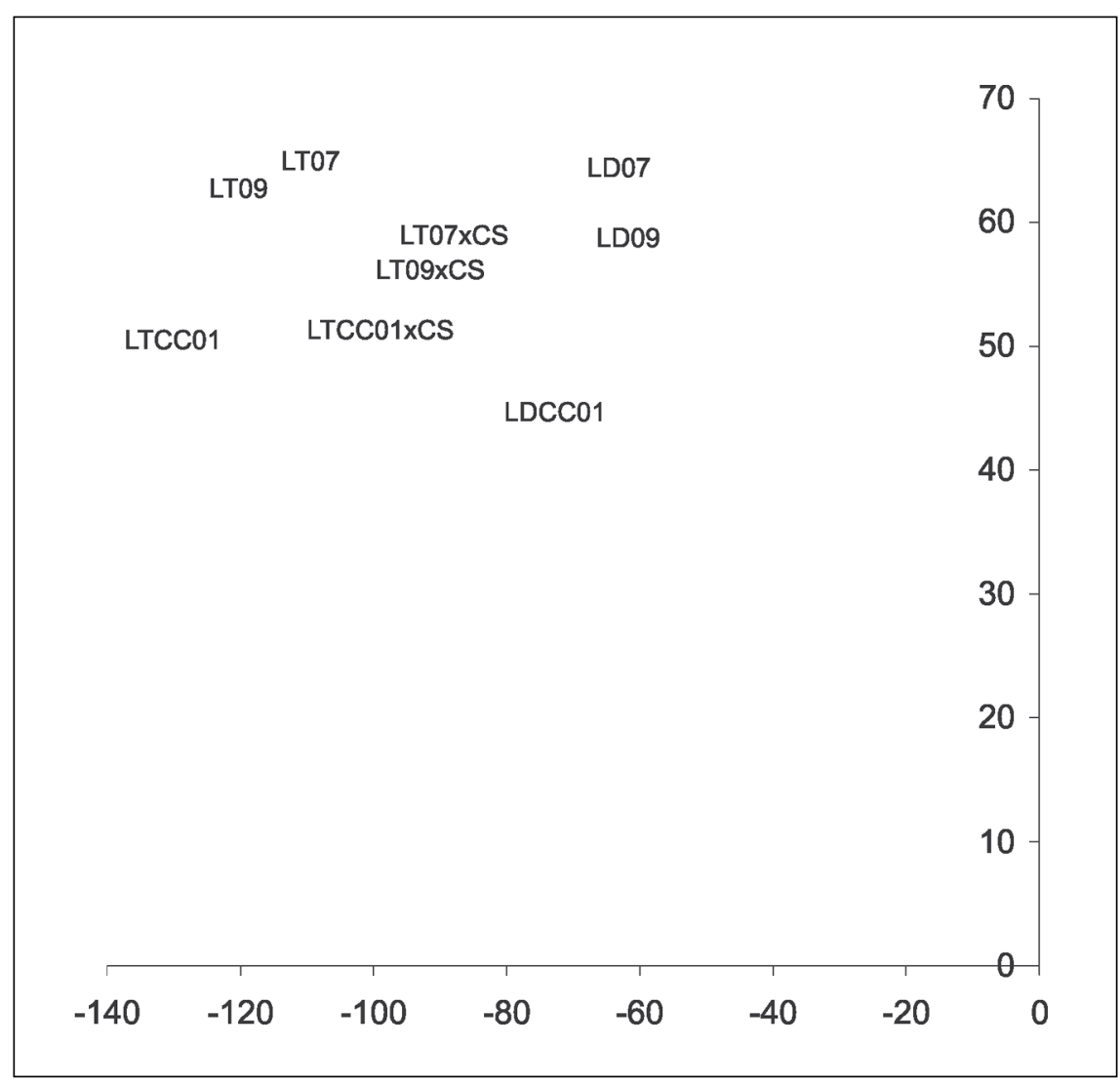

Figura 1. Dispersão gráfica de nove genótipos de melancia com diferentes níveis de ploidia, com base nos escores das duas primeiras variáveis canônicas. Petrolina, Embrapa Semi-Árido, 2000.

genitor Crimson Sweet.

Considerando o dendrograma estabelecido pelo método de Ward (Figura 2), evidenciou-se a formação de dois grupos principais, sendo o primeiro composto pelos genótipos diplóides e o segundo pelos poliplóides. Essa configuração indica que há maior semelhança entre plantas triplóides e tetraplóides, de modo que a distinção entre as plan- 


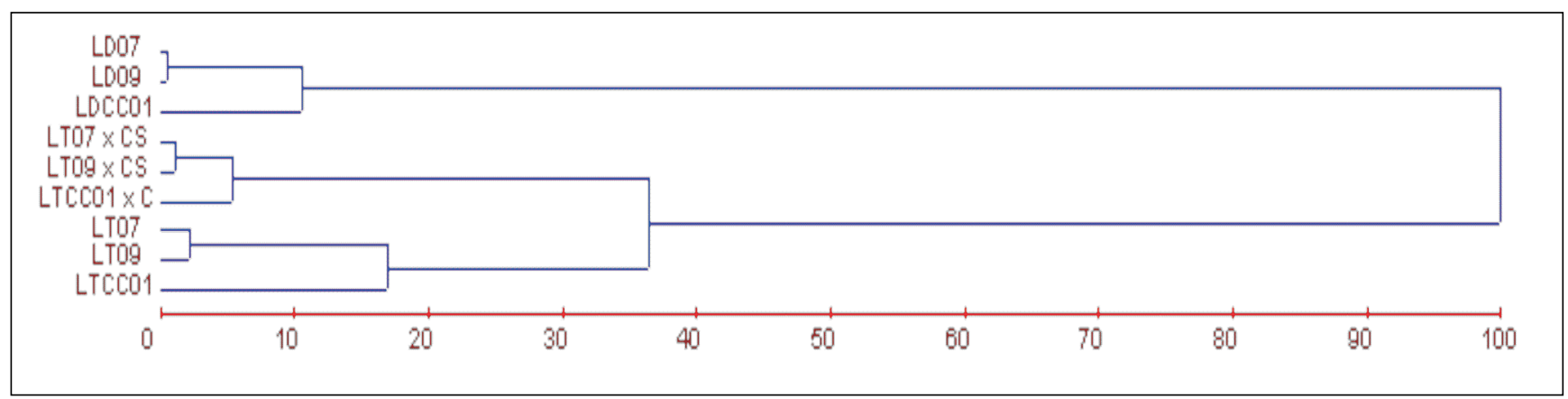

Figura 2. Dendrograma obtido por meio da análise de agrupamento de Ward, com base na distância generalizada de Mahalanobis, representativo das relações entre nove genótipos de melancia com diferentes níveis de ploidia. Petrolina, Embrapa Semi-Árido, 2000.

tas desses dois grupos e do grupo diplóide é facilmente realizada, com base nos caracteres estudados.

A análise das variáveis LF/CF, DCE, DCF, DCM, DOV, NCF e DT/DL, por meio de técnicas multivariadas, demonstrou que avaliação morfológica foi eficiente para a discriminação de plantas diplóides, triplóides e tetraplóides, constituindo-se portanto, numa importante ferramenta para auxiliar nos programas de melhoramento genético de melancia, que visem à obtenção de genótipos poliplóides. No entanto, convém mencionar que estas características podem ser influenciadas pelo ambiente e a análise individual de algumas variáveis poderá ocasionar a classificação equivocada de determinados genótipos em relação ao nível de ploidia. A contagem de cloroplastos em células estomáticas da epiderme foliar mostrou-se bastante confiável, tendo-se em vista a alta contribuição relativa para formação dos grupos e a ausência de variação intra-grupo.

Ainda que avaliação morfológica de plantas de melancia tratadas com colchicina possibilite apenas distinção entre indivíduos poliplóides e diplóides, a aplicação dessa técnica será indispensável, pois o descarte das plantas diplóides possibilitará considerável redução do número de plantas a serem submetidas à análise citogenética ou aos testes de progênie, reduzindo custos e acelerando o processo de seleção.

\section{LITERATURA CITADA}

CRUZ, C.D.; REGAZZI, A.J. Modelos Biométricos Aplicados ao Melhoramento Genético. Viçosa: UFV, Imprensa Universitária, 1997. $390 \mathrm{p}$.
GUERRA, M. O uso de Giemsa na citogenética vegetal - comparação entre a coloração simples e o bandeamento. Ciência e Cultura, v.35, n.2, p.190-193, 1983.

KIHARA, H. Triploid watermelon. Journal of the American Society of Horticultural Science, v.58, p.217-230, 1951.

QIN, X.; ROTINO, G.L. Chloroplast number in guard cells as ploidy indicator of in vitro-grown androgenic pepper plantlets. Plant Cell, Tissue and Organ Culture, v.41, p.145-149, 1995.

RAMALHO, M.A.P.; FERREIRA, D.F.; OLIVEIRA, A.C. Experimentação em Genética e Melhoramento de plantas. Lavras: UFLA, 2000. 326 p. SOUZA, F.F. Desenvolvimento e avaliação de híbridos triplóides de melancia [Citrullus lanatus (Thunb) Mansf.]. Recife: UFRPE. 2000. 121 p. (Tese mestrado) 